\title{
EFFECTIVENESS OF BOTULISM TOXIN IN THE TREATMENT OF ANAL FISSURE
}

\author{
Umar Bashir, Ahmed Raza*, Afsheen Zafar, Farhan Ahmed Majeed**, Hassan Shabbir, Moazzam Mumtaz
}

Islamic International Medical College Trush, Railway Hospital Rawalpindi Pakistan, *Combined Military Hospital, Kharian/National University of Medical Sciences (NUMS) Pakistan, ${ }^{* *}$ Combined Military Hospital, Multan/National University of Medical Sciences (NUMS) Pakistan

\section{ABSTRACT}

Objective: To assess the effectiveness, feasibility and acceptability of botulinum toxin in healing chronic anal fissures in our population.

Study Design: Prospective observational study.

Place and Duration of Study: Combined Military Hospital, Multan, from Jan 2019 till Dec 2019.

Methodology: Eighty patients were enrolled in the study out of which 72 completed the study. 33 IU of botulinum toxin A was injected in the intersphincteric groove in the perianal region. Outcome measures for effectiveness included pain score and fissure healing rates at 2, 6, 16 and 24 weeks after the injection. Healing rate was calculated as percentage and pre and post injection pain scores were compared by using paired sample t-test. Patient acceptability was assessed based on the proportion of patients who accepted the treatment. The average treatment cost was also calculated.

Results: A total number of 250 patients were found to be eligible for the study. A purposive sampling technique was used. Eighty patients took part in the study with an acceptability rate of $32 \%$. Seventy two patients completed the study with a completion rate of $90 \%$. Amongst 72 patients, $47(65.3 \%)$ were female and $25(34.7 \%)$ were male. The complete healing rate after 3 months of botulinum toxin injection was $49(68.1 \%)$. There was a significant reduction in pain scores at 2, 6, 16, and 24 weeks of study $(p<0.01)$.

Conclusion: The study supports that Botulinum toxin is an acceptable and effective treatment for anal fissure.

Keywords: Acceptability, Anal fissure, Botulinum toxin, Chemical sphincterotomy, Effectiveness.

This is an Open Access article distributed under the terms of the Creative Commons Attribution License (http://creativecommons.org/licenses/by/4.0), which permits unrestricted use, distribution, and reproduction in any medium, provided the original work is properly cited.

\section{INTRODUCTION}

Anal Fissure is defined as a laceration in the mucosa of the anoderm below the dentate line, commonly presenting with anal pain and bleeding per rectum ${ }^{1}$. The pathophysiology of the disease is not completely understood. Some suggest sphincter spasm causing ischemia of the posterior midline eventually resulting in fissure formation. It is also hypothesized to be the reason why fissures occur most commonly in the posterior midline 2,3 . Anal fissures are treated both medically and surgically. Medical treatment includes local ointments, bulk forming agents, painkillers and pharmacological agents that reduce either the sphincter tone or improve vascularity in the area. Although not considered the first line of treatment, surgical lateral internal sphincterotomy (LIS) has been considered the gold standard treatment ${ }^{4}$. Among Chemical agents used to relax sphincters, botulinum toxin is a newer agent as compared to the Nifidipine, Diltiazim (Calcium channel blockers) or GTN ointment. Botulinum toxin injection relaxes the anal sphincter tone by causing smooth muscle paraly-sis ${ }^{5,6}$.

Despite surgery being considered gold standard, it is not considered the first line of treatment because

Correspondence: Dr Umar Bashir, Resident Surgery, House 8B, Street 13, Sector F8/1, Islamabad Pakistan

Received: 10 Feb 2020; revised received: 07 May 2020; accepted: 18 May 2020 of its disadvantages, especially a small but permanent risk of incontinence ${ }^{7}$. The alternative medical treatment options including the botulinum toxin injection are therefore considered the initial line of management available for anal fissure and have almost similar healing rates ${ }^{7}$. Botulinum toxin injection had added advantages of ease of treatment (single injection vs daily use in case of other topical agents), avoidance of hospitalization, and lack of any significant side effects ${ }^{7}$.

Despite its widespread adoption in western world, botulinum toxin isn't used in routine in Pakistan for the treatment of chronic anal fissure. Although it can be very useful in our setup as a first line treatment because a single injection can relieve the symptoms. The issue of adherence to treatment which is there with other topical agents can be avoided with Botulinum thus making it an attractive option especially for those who have trouble applying an ointment multiple times a day. It does not require hospitalization or anesthesia thus having an overall lower cost of treatment in addition to better patient acceptability. However, studies on its effectiveness have hardly been done in our population ${ }^{8,9}$. Moreover, no study has been done to assess its feasibility or acceptability in our population.

Therefore, this study was designed to assess the effectiveness, feasibility and acceptability of 
botulinum toxin in healing chronic anal fissure in our population.

\section{METHODOLOGY}

A prospective Observational study was designed and carried out at Combined Military Hospital, Multan from January 2019 till Decemember 2019 after approval from the institutional ethical review board. The sample size was calculated assuming the healing rate of $56 \%$ with topical conservative management ${ }^{10}$, and expected healing rate of $74 \%$ with botulinum toxin ${ }^{11}$, from previous published studies with alpha at 0.05 and power at $90 \%$. Clincalc sample size calculator was used to calculate the sample size for this study ${ }^{12}$. A consecutive sampling technique was used. Data was collected on predesigned perfromas which included demographics, pain scores and findings of fissure examination on each follow up.

Anal fissure was diagnosed clinically in the outpatient department after which patients of both gender and above twelve years of age, who were willing to take part in the study were explained the procedure. Patients with any conditions associated with the fissures like fistula, perianal abscess, crohn's, ulcerative colitis, tuberculosis, HIV, radiation exposure, chemotherapy, any malignancy and any previous surgeries of the perianal region were excluded from the study.

Botulinum toxin A was used to inject into the intersphincteric groove palpated by hand with patients in lithotomy position. A total dose of 33 IU diluted in $1 \mathrm{ml}$ of isotonic saline was used on each patient. An insulin syringe was used to inject half of the dose on each side of the fissure without any local anesthesia. All of these procedures were done as outpatient procedures and patients were discharged immediately afterwards.

Patients were followed in outpatient clinics for a period of six months. The follow ups were scheduled at 2, 6, 16 and 24 weeks after the injection. The main outcome measures were the successful healing of the fissure and reduction in the pain score. On each follow up clinical examination was done and numerical pain score of the patient was recorded. On clinical examination the fissure was recorded as healed or non-healed. The numerical pain scale was recorded out of ten and the fissure healing as complete, partial and no healing. Patients without a complete response were then given an option for re-injection of the toxin after 3 months. Patients who didn't opt for a re-injection were either followed without injection for the 6 months or those patients who opted for surgery were counted as failures.

The average treatment cost was calculated for all three treatments (lateral internal sphincterotomy, medical treatment, botulinum toxin injections) being done in the department as cost incurred on patients for medicines.

Patient acceptability was calculated based on the proportion of patients who accepted the treatment out of the total number who were offered.

SPSS-21 was used for data entry and analysis. Frequencies were calculated for demographics of the studied population and the healing rate of the fissure. While pain scores before and after treatment were compared using paired sample t-test. A $p$-value $\leq 0.05$ was considered significant.

\section{RESULTS}

A total number of 250 patients with anal fissure were found to be eligible for the study. All the eligible patients were offered to take part in the study. The calculated sample size was 73 , however 80 patients were enrolled keeping in mind an expected $10 \%$ attrition rate in follow up period. Eighty patients willingly, after informed and written consent took part in the study with an acceptability rate of $32 \%$.

Out of the total, 72 completed the study with a completion rate of $90 \%$. Forty seven $(65.3 \%)$ were female and $25(34.7 \%)$ were male. Average age of the patients was $44.78 \pm 15.4$ years. Out of a total of 72 , $49(68.1 \%)$ patients showed complete healing after 3 months of botulinum toxin injection (table-I).

We used Botulinum toxin A injection which costs around 19000 Pakistani rupees, containing 100 IU of toxin divided among three patients. Botulinum injec-

Table-I: Healing rate at 6 months.

\begin{tabular}{l|c|c}
\hline & Frequency & Percentage \\
\hline Healing & 49 & 68.1 \\
\hline Non-healing & 23 & 31.9 \\
\hline
\end{tabular}

There was a significant reduction in pain scores at all follow-ups ( $p$ value $<0.01$ ).

Table-II: Comparison of pain scores.

\begin{tabular}{l|c|c|c|c}
\hline & $\begin{array}{c}\text { Mean } \pm \\
\text { SD }\end{array}$ & t & Df & $\begin{array}{c}\text { Sig. (2- } \\
\text { tailed) }\end{array}$ \\
\hline $\begin{array}{l}\text { Pair 1- Pain score } \\
\text { at 2 weeks }\end{array}$ & $2.90 \pm 1.71$ & 14.38 & 71 & 0.000 \\
\hline $\begin{array}{l}\text { Pair 2- Pain score } \\
\text { at 6 weeks }\end{array}$ & $4.71 \pm 1.83$ & 21.78 & 71 & 0.000 \\
\hline $\begin{array}{l}\text { Pair 3- Pain score } \\
\text { at 12 weeks }\end{array}$ & $4.99 \pm 2.11$ & 20.09 & 71 & 0.000 \\
\hline
\end{tabular}


tion thus costs each patient around 6333 rupees. A lateral sphincterotomy cost was calculated to be a minimum of 12000 rupees in our set up at the time of the study and medical treatment with GTN ointment cost an average of 2000-3000 rupees for an average healing time of 4 to 6 weeks at the time of the study.

\section{DISCUSSION}

Historically, anal fissure was thought to be caused due to constipation and passage of hard stool. But, $>25 \%$ of patients with chronic anal fissures give history of constipation ${ }^{13}$. Diarrhoea is also known as a predisposing factor in up to $7 \%$ of patients ${ }^{13}$.

Recently, increased tonicity of the internal sphincter is believed to be the cause for anal fissures. Several reports have documented elevated resting anal pressures in fissure patients with values above $90 \mathrm{mmHg}$. Additionally, the elevated anal pressure causes ischemia of the posterior commissure and reduces the anodermal blood flow ${ }^{14}$. Therefore botulinum toxin was introduced as the treatment because it relaxes the internal anal sphincter when injected into it by causing temporary synaptic blockade (reversible denervation). This leads to a decrease of the anal pressure allowing the time for fissure to heal. Botulinum toxin is similar to surgical sphincterotomy in that matter, without the disadvantage of an anatomical disruption of the internal anal sphincter ${ }^{15}$. Botulinum toxin injection into the intersphincteric groove was first described by Josh and Schmrigk ${ }^{16}$. No manometric data was gathered in our study, but Botulinum toxin has already shown to lower the anal sphincter tone ${ }^{17,18}$.

In our study, $68.1 \%$ of the patients reported complete fissure healing. Meta analysis of four different studies, which included 279 patients showed a comparable healing rate of $65 \%$ for botulinum in chronic anal fissure ${ }^{19}$. A very few local studies are available in this context but a study done by Iqbal et al, in 2014 showed better efficacy in terms of healing with Botulinum toxin injection $(83.4 \%)$ as compared to lateral Internal sphincterotomy $(75.8 \%)^{8}$. Studies by Maria et al, in 1998 and Gui et al, in 1994 have reported a healing rate of anal fissure ranging from $60-70 \%$ after a single injection of 15 or 20 units of the botulinum toxin ${ }^{11,20}$. Our study show that bolulinum toxin produces a significant and superior reduction in pain associated with the anal fissures supported by the study from Amormin et $a l$, which show similar result with improved pain score after botulinum toxin injection ${ }^{21}$.

In our study, we used a dose of 33 IU of botulinum toxin. We opted for a convenient dosage that was neither too high nor too low as compared to literature available and was cost effective for our patients. A study by Glover et al, in 2015 has shown no association of pain reduction or healing with the dosage used which has varied from 15-80 units in various studies 22 , while others have proven the benefits of giving higher dosage of the toxin. In a trial by Maria et al, involving 57 patients injected with 15 or 20 units of botulinum toxin, the higher dose was more effective with respect to long-term healing with no associated higher rate of complication $^{23}$.

In terms of cost, GTN ointment was the cheapest method of treatment, costing around 2000-3000 rupees for a treatment spanning 4-6 weeks in our study. But patient compliance was very poor since it requires a daily application of the ointment. As compared to medical ointments Botulinum toxin used in a low dose is cheaper and more acceptable option if a single Botulinum toxin injection was used but for a second injection the cost became high for most patients and none of our patients opted for a second dose even after incomplete response and non healing fissures. Even though a second botulinum toxin injection has shown to improve the healing rate to as high as $95 \%$ in various studies ${ }^{18,24}$.

Another probable reason for not opting for a second injection is the strong notion in our set up that surgery would relieve their symptoms faster so patients usually choose surgeries, overlooking the side effects associated with it. The most common complication of lateral internal sphincterotomy is Incontinence. Incontinence rates vary between 0 and $36 \%$ for gas, 0 and $21 \%$ for liquid stool and 0 and $5 \%$ for solid stool 25 . In our study and supported by many others Botulinum toxin injection didn't require any admission, anesthesia, didn't disrupt a patient's daily routine and provided early relief, thus was attractive to a strata of population. None of our patients had any short or long term complications associated with the procedure.

\section{LIMITATION OF STUDY}

Absence of a control group, observer bias, no anorectal manometeric readings were some of the limitations of our study.

\section{CONCLUSION}

This study supports the notion already supported by many that Botulinum toxin is an effective treatment for anal fissure. It has comparable healing rate to other available treatment options and results in significant reduction in pain after a single injection. It is cost effec- 
tive if low doses are used and feasible and can be an attractive alternative to surgery with fewer complications.

\section{CONFLICT OF INTEREST}

This study has no conflict of interest to be declared by any authors.

\section{REFERENCES}

1. Brady JT, Althans AR, Neupane R, Dosokey EM, Jabir MA, Reynolds HL, et al. Treatment for anal fissure: Is there a safe option? The Am J Surg 2017; 214(4): 623-28.

2. Witte ME. Botulinum toxin A injection in ISDN ointment-resistant chronic anal fissures. Digest Surg 2007; 24(3): 197-201.

3. Schouten WR, Briel JW, Auwerda JJ. Relationship between anal pressure and anodermal blood flow. Diseas Colon Rec 1994; 37(7): 664-69.

4. Acar T, Acar N, Güngör F, Kamer E, Güngör H, Candan MS, et al. Treatment of chronic anal fissure: Is open lateral internal sphincterotomy (LIS) a safe and adequate option?. Asian J Surg 2019; 42(5): 628-33.

5. Jankovic J, Brin MF. Therapeutic uses of botulinum toxin. New Eng J Med 1991; 324(17): 1186-94.

6. Brisinda G, Sivestrini N, Bianco G, Maria G. Treatment of gastrointestinal sphincters spasms with botulinum toxin A. Toxins 2015; 7(6): 1882-16.

7. Keighley M RB. Ano-rectal disorders. In: Fischer J E, ed. Fischer's mastery of surgery. $7^{\text {th }}$ ed. Philadelphia: Wolters-Kluwer; 2019. 5562-5565.

8. Iqbal Z, Khan K, Khan S, Shareef G, Saboor Z, Amin A. Management of chronic anal fissures. J Med Sci 2016; 24(2): 64-68.

9. ul Islam U. Is Injection of Botulinum Toxin a Treatment of Choice for Chronic Anal Fissure?. J Surg Pak Inter 2013; 18(1): 1-5.

10. Salem AE, Mohamed EA, Elghadban HM, Abdelghani GM. Potential combination topical therapy of anal fissure: development, evaluation, and clinical study. Drug Deliv 2018; 25(1): 1672-82.

11. Maria G, Cassetta E, Gui D, Brisinda G, Bentivoglio AR. A comparison of botulinum toxin and saline for the treatment of chronic anal fissure. New Eng J Med 1998; 338(4): 217-20.

12. Kane SP. Sample Size Calculator. 2019 Available from: https:// clincalc.com/stats/samplesize.aspx.
13. Collins EE, Lund JN. A review of chronic anal fissure management. Tech Coloproctol 2007; 11(3): 209-12.

14. Fahadullah M, Peirce C. Fissure-In-Ano. In: Cianci P. Proctological Diseases in Surgical Practice (book on the internet). Intech Open; 2018. Available from: https://www.intechopen.com/ books/proctological-diseases-in-surgical-practice/fissure-in-ano.

15. Soll C, Dindo D, Hahnloser D. Combined fissurectomy and botulinum toxin injection. A new therapeutic approach for chronic anal fissures. Gastroenterol Biol 2008; 32(6-7): 667-70.

16. Jost $\mathrm{WH}$, Schimrigk $\mathrm{K}$. Use of botulinum toxin in anal fissure Diseas Colon Rec 1993; 36(10): 974-78.

17. Giral A, Memişoglu K, Gültekin Y, İmeryüz N, Kalaycı C, Ulusoy $\mathrm{NB}$, et al. Botulinum toxin injection versus lateral internal sphincterotomy in the treatment of chronic anal fissure: a non-randomized controlled trial. BMC Gastroenterol 2004; 4(1): 7-10.

18. Mínguez M, Melo F, Espí A, García-Granero E, Mora F, Lledó S, et al. Therapeutic effects of different doses of botulinum toxin in chronic anal fissure. Dis Colon Rec 1999; 42(8): 1016-21.

19. Sajid MS, Hunte S, Hippolyte S, Kiri VA, Maringe C, Baig MK. Comparison of surgical vs chemical sphincterotomy using botulinum toxin for the treatment of chronic anal fissure: a meta analysis. Colorectal Dise 2008; 10(6): 547-52.

20. Gui D, Anastasio G, Maria G, Cassetta E, Bentivoglio AR, Albanese A. Botulinum toxin for chronic anal fissure. Lancet 1994; 344(8930): 1127-28.

21. Amorim H, Santoalha J, Cadilha R, Festas MJ, Barbosa P, Gomes A. Botulinum toxin improves pain in chronic anal fissure. Porto Biomedical J 2017; 2(6): 273-76.

22. Glover PH, Tang SI, Whatley JZ, Davis ED, Jex KT, Wu R, et al. High-dose circumferential chemodenervation of the internal anal sphincter: A new treatment modality for uncomplicated chronic anal fissure: A retrospective cohort study (with video). Inter J Surg 2015; 23(1): 1-4.

23. Maria G, Brisinda G, Bentivoglio AR, Cassetta E, Gui D. Botulinum toxin injections in the internal anal sphincter for the treatment of chronic anal fissure: long-term results after two different dosage regimens. Annals Surg 1998; 228(5): 664-68.

24. Ravindran P, Chan DL, Ciampa C, George R, Punch G, White SI High-dose versus low-dose botulinum toxin in anal fissure disease. Tech Coloproctol 2017; 21(10): 803-8.

25. Lindsey I, Jones OM, Cunningham C, Mortensen NM. Chronic anal fissure. British J Surg 2004; 91(3): 270-09. 